\title{
COMMENTARY
}

\section{Teaching Ethics: See One, Do One, ... Teach One?}

\author{
Brian L. Erstad, PharmD, ${ }^{\text {a }}$ Timothy P. Stratton, $\mathrm{PhD}^{\mathrm{b}}$ \\ ${ }^{a}$ University of Arizona, College of Pharmacy, Tucson, Arizona \\ ${ }^{\mathrm{b}}$ University of Minnesota, College of Pharmacy, Duluth, Minnesota
}

Corresponding Author: Brian L. Erstad, University of Arizona, College of Pharmacy, 1295 N. Martin Ave., P.O. Box 210202, Tucson, AZ 85721-0202. Tel: 520-694-5600. Email: erstad@pharmacy.arizona.edu

Submitted December 8, 2020; accepted March 23, 2021; ePublished April 2021

\begin{abstract}
All faculty members should have a general understanding of the field of ethics, regardless of any formal training, since instruction and training in ethical decision-making is an accreditation expectation. Additionally, whether they recognize it or not, pharmacy faculty members are involved in ethical decision-making on an almost daily basis. The aims of the current commentary are to expand on a basic approach to ethical decision-making using examples involving students or faculty members in each of the triad areas of teaching, research, and service, and serve as a starting point to enable all faculty to teach students how to work through an ethical dilemma. In particular, this commentary will focus on the initial steps involved in determining if an ethical dilemma exists, determining the facts related to the dilemma by identifying technical facts and legal constraints, and identifying the principles and values that play a role in the situation decide which are in conflict. References are provided for more in-depth review of ethics subject matter beyond the scope of this commentary.

Keywords: ethical issues, clinical, academic
\end{abstract}

\section{INTRODUCTION}

All faculty members should have a general understanding of the field of ethics, even if they have had no formal training in the field, since instruction and training in ethical decision-making is an accreditation expectation by the Accreditation Council for Pharmacy Education (ACPE) for students and by the American Society of Health-System Pharmacists (ASHP) for residents. ${ }^{1,2}$ Additionally, whether they recognize it or not, pharmacy faculty themselves are involved in ethical decision-making on an almost daily basis.

No published research documents the preparation of U.S. pharmacy faculty in the area of teaching ethics. One recent study in Australia and New Zealand revealed a lack of faculty expertise, a dearth of resources, and a lack of standardization in teaching ethics in schools of pharmacy in those countries. ${ }^{3}$ However, these findings are not necessarily applicable to U.S. colleges and schools of pharmacy. For example, the Australian study cited a lack of pharmacy ethics syllabi; ${ }^{3}$ however, the AACP Health Care Ethics Special Interest Group hosts a library of structured syllabi (including learning objectives) which at the time of this commentary included syllabi from 15 different ethics courses. ${ }^{4}$

In the U.S., there is a need for the Academy to examine faculty training and qualifications for teaching ethics, and how ethics is taught and assessed, as this information is currently unavailable. As educators and mentors, pharmacy educators should have the same foundations for ethical decision-making that we expect of our students.

The situation does not appear to be much better in medicine, as discussed in a review of medical ethics education in Western English-speaking countries. ${ }^{5}$ Ethics education in medicine is focused primarily on cognitive (ie, competency) and attitudinal (ie, virtue) objectives; however, ethics coursework is not mandatory, and a shortage of faculty with expertise in ethics is a major challenge in implementing ethics in the curriculum. ${ }^{5}$

How do faculty who are relatively unfamiliar with the field of ethics teach others about ethical behavior? For interested faculty, several useful websites provide definitions and descriptions of important terms related to philosophical issues including ethics. ${ }^{6-8}$ In particular, a Brown University website provides an excellent distillation of the important issues related to decisions about what is right or wrong. ${ }^{7}$ These sites have information on ethical decision-making that is not specific to pharmacy, but they can provide for a foundational understanding of ethics which can supplement the limited number of available publications on ethics instruction more specific to pharmacy education. ${ }^{9-13}$

Of the pharmacy-specific ethics instruction articles, two involved research involving elective courses, one evaluating the use of debates to deliver ethics content to undergraduate pharmacy students in the United Kingdom, ${ }^{9}$ and the other evaluating the use of facilitated discussion groups to deliver ethical content. ${ }^{10} \mathrm{~A}$ third article described a structured format for teaching ethics and professionalism, ${ }^{11}$ and a fourth discussed ethical and legal issues pertaining to 
social media. ${ }^{12}$ Stratton discussed evidence from other health professions demonstrating that multiple exposures to ethics is preferred over a single course. ${ }^{13}$ Additionally, Stratton provided a decision-making approach to working through ethical dilemmas that can be utilized by any faculty who are familiar with basic ethics principles, rather than relying on a single faculty member with recognized expertise.

The aims of the current commentary are to expand on the basic approach to ethical decision-making provided by Stratton, using examples involving students or faculty members in each of the triad areas of teaching, research, and service, ${ }^{12}$ and serve as a starting point to enable all faculty to teach students how to work through an ethical dilemma. In particular, this commentary will focus on the initial three steps of the Stratton approach that concern identifying an ethical dilemma, determining the facts of the dilemma, and identifying the principles and values that play a role in the dilemma. References are provided for more in-depth review of some of the subject matter beyond the scope of this commentary.

\section{Step One: Determine if an Ethical Dilemma Exists}

Using teaching as an example, ethical issues commonly faced by educators include problems such as professionalism or fairness concerns raised by students about testing and other forms of assessment. Lack of professionalism may be manifest by student or faculty behavior that is disrespectful (including email messages or postings on social media), breaks a promise (eg, faculty failure to follow the syllabus) or threatens existing or future relationships. Issues of fairness can arise where faculty or student actions could lead to harm (emotional or physical; or in case-based situations, theoretical), or where an action might compromise somebody's rights by providing one party with an unfair advantage (eg, cheating). As discussed by Stratton, ${ }^{13}$ questions to consider in this step relate to issues such as fairness, promises, harm, relationships, rights, benefits, and respect. Where any of these concepts have been violated, the situation constitutes an ethical dilemma, and one moves on to the next step.

Step Two: Determine the Facts Related to the Dilemma

Technical facts may need clarification and should not be confused with differences of opinion. Using the example of human subjects' research, there are differences of opinion as to the optimal application of general ethical principles (ie, respect for persons, beneficence, justice) in any specific study, but the need to consider all of these principles when considering and conducting such research is not debatable. Additionally, legal, regulatory, or policy constraints on the behavior or behaviors leading to the dilemma need consideration. For example, faculty conducting research involving human subjects are required to receive training in the ethical principles underlying federal regulations that protect research participants, the foundations of which are presented in the Belmont Report. ${ }^{14}$

The basic ethical principles discussed in the Belmont Report include respect for persons; beneficence; and justice as applied to informed consent procedures, assessments of risks and benefits, and equitable selection of subjects. Respect for persons requires that researchers acknowledge and treat individuals as autonomous, and protect individuals whose autonomy is limited. Beneficence obligates researchers to treat persons in an ethical manner by respecting their decisions, protecting them from harm, and securing their well-being. Justice obligates researchers to treat people fairly with equitable distribution of burdens and benefits.

In common with ethical decision-making in research contexts, applying these principles to arrive at an ethically permissible decision may lead one to recognize that at times the principles may present as competing claims. Such a quandary necessitates using a balanced approach that may not resolve all ethical concerns. An example involving teaching is useful to illustrate the latter point. Assume that the professional code of a school of pharmacy has a clause related to justice (fairness), which mandates students to report cheating by other students. A student who reports cheating may worry that it could lead to some sort of retribution (ie, harm) by the student accused of cheating. Both justice and beneficence (maximizing benefit, limiting harm) are core ethical principles, but in this scenario they conflict with each other. A professionalism committee involved in this situation may need prioritize one of these core principles over the other, unless additional confirmation of cheating from another source is available.

With regards to service, many institutions of higher learning have professional conduct policies that address ethics standards for integrity, honesty, and fairness by faculty. While acknowledging academic freedom, these policies often refer to responsibilities associated with civil discourse when participating in university service activities. Examples of such responsibilities include treating other individuals with dignity and respect, being compassionate and courteous (eg, not monopolizing a conversation), and exhibiting the previously mentioned characteristics of integrity, honesty, and fairness. Similarly, all of the major pharmacy organizations either have codes of ethics or ethical standards for behavior as part of their core values. Failure to abide by these codes and standards in either the academy or profession may have legal implications. ${ }^{15-18}$

Step Three: Identify the Principles and Values that Play a Role 
Are the personal, professional, institutional or societal values of the moral agents on either side of the dilemma in conflict with one another? Returning to the question of professional behavior, is the behavior or behaviors of one party in conflict with behavior that would be expected of all others in a similar cohort? Expected behaviors by individual students and faculty in the classroom might be stipulated in a course syllabus. At the institutional level, a university's Faculty Handbook might outline expected faculty behaviors regarding the free exchange of ideas at campus events, or a practice site's policies and procedures might proscribe certain responses to specific patient requests. A profession's Code of Ethics outlining expected behaviors for student pharmacists and preceptors might reflect societal expectations of that profession. With respect to professionalism, the reader is referred to a number of papers in AJPE that discuss professionalism attributes and ways to promote and assess it in students in the didactic and experiential settings. ${ }^{19-22}$

Similar to issues of professionalism, many faculty members have encountered student concerns and complaints about the fairness (justice) of assessments. Unfortunately, there is no professional consensus on ethical judgments related to assessments, although there is general agreement that one of the keys to avoiding complaints of unfairness is to provide clear verbal and written expectations and guidance at the beginning of coursework and to employ valid assessments consistent with course objectives. ${ }^{23}$ More specific guidance is available in papers published in AJPE that address issues of testing and other forms of assessment. ${ }^{24-27}$

Remaining Steps of the Basic Approach to Decision Making

There are seven remaining steps in the basic ethical decision-making process by Stratton ${ }^{13}$ that cannot be adequately covered in this brief commentary, but might be appropriate for an AACP webinar series (Table 1). Step 4: Identify your goal in resolving the dilemma. What do you hope to accomplish, keeping in mind that any well-defined goal is specific, measurable and time-bound, and as a resolution to an ethics problem, should be as fair as possible to all parties involved. Step 5: Generate potential reasonable solutions to the dilemma. This is a brainstorming exercise - what could be done? Step 6: Using ethical concepts and principles, analyze the pros and cons of each alternative. Faculty who are more familiar enough with basic ethics terminology, codes of ethics and possibly the teachings of some philosophers will be in the best position to students work through this step. Step 7: Select one of the alternatives. Based on the analysis undertaken in the previous step, what should be done? This step is often skipped by students who are reluctant to commit to a tough decision. Faculty and students alike must learn to become comfortable with "commitment with uncertainty:" One commits to a course of action despite lingering doubts that because of incomplete information, there may be a better choice that has not been considered. ${ }^{28}$ Step 8: Anticipate potential objections to the selected course of action. This exercise helps ensure that a person has considered both sides of a dilemma as well as potential adverse consequences arising from the approach chosen to resolve the dilemma. Step 9: Evaluate the results. Of course, this activity needs to occur after a solution has been implemented. While possible to undertake in a live situation, evaluating results is generally not possible in a classroom scenario unless the scenario incorporates an extended timeline that updates the situation based on the selected course of action. Step 10: Address how could this ethical dilemma have been avoided in the first place. "Hindsight being 20-20," upon reflection, what steps might have been taken earlier to prevent this dilemma from arising in the first place?

\section{CONCLUSION}

All faculty should have a general understanding of ethics principles and of the ethical problem-making process, since ethical issues arise in during teaching, research, and service activities. In contrast to specialized research or practice skills, working through an ethical dilemma is a general skill that every faculty member should possess, and should be able to teach. Helpful web-based resources are available that can provide faculty members with a general background needed for the ethics decision-making process. ${ }^{6-8}$ 


\section{REFERENCES}

1. Accreditation Council for Pharmacy Education. Accreditation Standards and Key Elements for the Professional Program in Pharmacy Leading to the Doctor of Pharmacy Degree ("Standards 2016"). Published February 2015. https://www.acpe-accredit.org/pdf/Standards2016FINAL.pdf. Accessed February 24, 2021.

2. ASHP. Accreditation Standards for PGY1 Pharmacy Residencies. Standard effective 2016. https://www.ashp.org/Professional-Development/Residency-Information/Residency-ProgramResources/Residency-Accreditation/Accreditation-Standards-for-PGY1-Pharmacy-Residencies. Accessed February 24, 2021.

3. Beshara S, Herron D, Moles RJ, Chaar B. Status of Pharmacy Ethics Education in Australia and New Zealand. Am J Pharm Educ. 2020 Mar;84(3):7452. doi: 10.5688/ajpe7452

4. American Association of Colleges of Pharmacy. AACP Connect. Health Care Ethics Special Interest Group. https://connect.aacp.org/communities/groupdetails/librarydocuments?communitykey=0b8a1c60-a937-4780-b0ad3854d2db3de3\&tab=librarydocuments\&LibraryFolderKey=\&DefaultView= Accessed February 28, 2021.

5. Giubilini A, Milnes S, Savulescu J. The medical ethics curriculum in medical schools: Present and future. J Clin Ethics. 2016;27(2):129-145.

6. Zalta EN. The Stanford Encyclopedia of Philosophy. Stanford University, Center for the Study of Language and Information, The Metaphysics Research Lab. https://plato.stanford.edu/. Accessed February 24, 2021.

7. Brown University. A Framework for Making Ethical Decisions. https://www.brown.edu/academics/science-andtechnology-studies/framework-making-ethical-decisions. Accessed February 24, 2021.

8. Fieser J. Ethics. Internet Encyclopedia of Philosophy. https://www.iep.utm.edu/ethics/. Accessed February 24, 2021.

9. Hanna LA, Barry J, Donnelly R, et al. Using debate to teach pharmacy students about ethical issues. Am J Pharm Educ. 2014;78(3):57. https://doi:10.5688/ajpe78357

10. Malcom DR. Teaching and assessing clinical ethics through group reading experience and student-led discussion. Curr Pharm Teach Learn. 2018 May;10(5):602-610. https://doi:10.1016/j.cpt1.2018.01.009

11. Horton ER, Morin A, Pervanas HC, Mukherjee SM, Belliveau P. A novel structured format for engaging pharmacy students in bioethics discussions. Am J Pharm Educ. 2014;78(9):171. https://doi:10.5688/ajpe789171

12. Cain J, Fink JL. Legal and ethical issues regarding social media and pharmacy education. Am J Pharm Educ. 2010;74(10):184. https://doi:10.5688/aj7410184

13. Stratton TP. Incorporating ethics content throughout an integrated pharmacy curriculum. Am J Pharm Educ. 2020;84(11):Article 7865. https://doi.org/10.5688/ajpe7865

14. U.S. Department of Health \& Human Services. The Belmont Report. https://www.hhs.gov/ohrp/regulations-andpolicy/belmont-report/read-the-belmont-report/index.html. Accessed February 24, 2021.

15. APhA. Code of Ethics. https://www.pharmacist.com/code-ethics?is_sso_called=1. Accessed February 24, 2021.

16. ASHP. Ethics. https://www.ashp.org/Pharmacy-Practice/Policy-Positions-and-Guidelines/Browse-byTopic/Ethics?loginreturnUrl=SSOCheckOnly. Accessed February 24, 2021.

17. ACCP. Mission and Strategy. https://www.accp.com/about/mission.aspx. Accessed February 24, 2021.

18. AACP. Mission, Vision, Values. https://www.aacp.org/article/mission-vision-values. Accessed February 24, 2021.

19. Zeeman JM, Kiser SN, Steeb DR, Hubal R. Identifying priority student leadership and professionalism attributes among faculty, preceptors, and students via modified Delphi. Am J Pharm Educ. 2020;84(11).Article 8076. https://doi.org/10.5688/ajpe8076

20. Schwartz A, Ruble M, Sellers KC, Rodriguez-Snapp N, Hill A, Tipparaju S. Incorporation of professionalism expectations and evaluative processes within a college of pharmacy. Am J Pharm Educ. 2018;82(5):Article 6478. https://doi.org/10.5688/ajpe6478

21. Smith KJ, Flaxman C, Farland MZ, et al. Development and validation of a situational judgement test to assess professionalism. Am J Pharm Educ. 2020;84(7):ajpe7771. https://doi:10.5688/ajpe7771

22. Vos SS, Sabus A, Seyfer J, Umlah L, Gross-Advani C, Thompson-Oster J. Using continuing professional development to create meaningful co-curricular learning opportunities for all student pharmacists. Am J Pharm Educ. 2018;82(4):6270. https://doi: 10.5688/ajpe6270

23. Green SK, Johnson RL, Kim DH, Pope NS. Ethics in classroom assessment practices: Issues and attitudes. Teach Teach Educ. 2007;23:999-1011. https://doi:10.1016/j.tate.2006.04.042

24. Yang BW, Razo J, Persky AM. Using Testing as a Learning Tool. Am J Pharm Educ. 2019;83(9):7324. https://doi: 10.5688/ajpe7324

25. Janke KK, Kelley KA, Martin BA, Ray ME, Sweet BV. Identifying high-impact and managing low-impact assessment practices. Am J Pharm Educ. 2019;83(7):7496. https://doi.org/10.5688/ajpe7496 
26. Gilliam EH, Brunner JM, Nuffer W, Patel TC, Thompson ME. Design and content validation of three settingspecific assessment tools for advanced pharmacy practice experiences. Am J Pharm Educ. 2019;83(9):7067. https://doi: 10.5688/ajpe7067

27. Poirier TI, Wilhelm M. Scholarly and best practices in assessment. Am J Pharm Educ. 2018;82(3):6769. https://doi.org/10.5688/ajpe6769

28. Cribb A. Managing ethical uncertainty: implicit normativity and the sociology of ethics. Sociology of Health Illness. 2019;42(S1):21-34. https://onlinelibrary.wiley.com/doi/10.1111/1467-9566.13010. Accessed, March 1, 2021.

Table 1. An Approach to Working Through Ethical Dilemmas.

A dilemma is a problem where there is a conflict of values where there is no clear right or wrong answer. There may also be a conflict with a statute or rule when these seem arbitrary or unjust. A choice must be made between two or more moral or ethical goods. If there is a clear course of action, then there is no dilemma.

1. Determine if an ethical dilemma exists.

Is the situation unfair? To whom?

Does the situation break a promise?

Will the situation result in harm? To whom?

Will the situation threaten existing or future relationships? With whom?

Does the situation compromise someone's rights?

Will a possible action benefit the patient?

Is the situation disrespectful? To whom?

2. Determine the facts related to the dilemma by identifying:

Technical facts

Clarify the facts if necessary

Do not confuse facts with differences in opinion

Legal constraints

3. Identify the principles and values that play a role in the situation and decide which are in conflict:

Personal values

Professional values

Institutional values

Societal values

4. IDENTIFY YOUR GOAL in resolving the dilemma. (What do you hope to accomplish?)

5. Generate potential reasonable solutions to the dilemma. (What could be done?)

6. Using ethical concepts and principles, analyze the pros and cons of each alternative.

7. Select one of the alternatives. (What should be done?)

8. Anticipate potential objections to the selected course of action.

9. Evaluate the results.

10. Address how could this ethical dilemma have been avoided in the first place. 